\title{
Pequenos deslocamentos: corpo, arte, saúde e educação
}

\author{
Small displacements: body, art, health and education
}

DOI: http://dx.doi.org/10.5965/198431781642020196

\author{
Flavia Liberman \\ Universidade Federal de São Paulo - UNIFESP \\ f.liberman@unifesp.br | ORCID | LATTES
Marina Guzzo
Universidade Federal de São Paulo - UNIFESP marina.guzzo@unifesp.br | ORCID | LATTES \\ Elizabeth Maria Freire de Araújo Lima \\ Universidade de São Paulo - USP \\ beth.araujolima@gmail.com | ORCID | LATTES
}

\section{RESUMO}

Este artigo pretende problematizar a ideia de pequenos deslocamentos que são experimentados no contexto de práticas de formação que buscam compor outros modos de pensar e atuar em saúde, como possibilidade de promover acesso à experiência estética e à vida em sua potência expressiva e de criação. Para tanto apresentaremos alguns aspectos de um projeto de criação e educação que envolve mulheres de uma região vulnerável de Santos, que apresentam diferentes desafios de ordem física, emocional e social ${ }_{1}$ e os estudantes de uma universidade pública. Neste projeto, foram realizadas diferentes propostas mobilizadas pelas artes em suas múltiplas linguagens, com o intuito de promover experiências sensíveis e lúdicas que possam produzir pequenos deslocamentos, vivificar os corpos, ativar memórias, imaginações, reconhecer e despertar desejos, afetar e ser afetado pelo encontro entre corpos. Consideramos os pequenos deslocamentos como movimentos menores dentro das experiências $_{2}$ que tem a potência de ativar e incidir em processos de subjetivação e produção de outras sensibilidades. Experimentamos o dançar, o cantar, jogar, dramatizar, mover e pausar, conversar e silenciar entre outras proposições atentos aquilo que é pequeno, as marcas microscópicas, aos detalhes dos acontecimentos. Ancoradas em uma perspectiva micropolítica, apostamos nas pequenas interferências como modo de produzir uma formação inventiva para os alunos e o aumento de potência individual e coletiva com todos e todas as participantes, deste projeto colaborativo que se efetua na interface corpo, arte, saúde e educação.

Palavras-chave: Arte; Mulheres; Território; Educação; Saúde;

\section{ABSTRACT}

This article intends to problematize the idea of small displacements that are experienced in the context of training practices that seek to compose other ways of thinking and acting in health, as a possibility to promote access to aesthetic experience and life in its expressive and creative power. To this end, we will present some aspects of a creation and education project that involves women from a vulnerable region of Santos, who present different physical, emotional and social challenges, and students from a public university. In this project, different proposals were made mobilized by the arts in their multiple languages, in order to promote sensitive and 


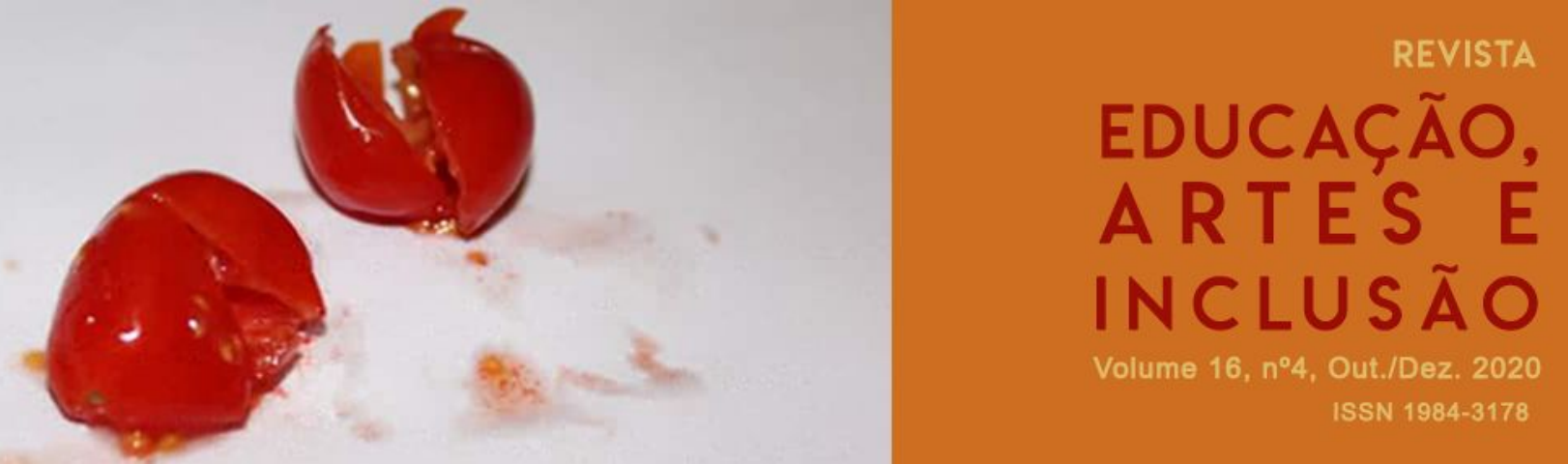

playful experiences that can produce small displacements. quicken bodies, activate memories, imaginations, recognize and awaken desires, affect and be affected by the encounter between bodies. We consider small displacements as minor movements within experiences, which have the power to activate and affect processes of subjectivation and the production of other sensitivities. We experimented dancing, singing, playing, dramatizing, moving and pausing, talking and silencing, among other things, attentive to what is small, the microscopic marks, to the details of events. Anchored in a micropolitical perspective, we bet on small interferences as a way of producing inventive training for students and the increase of individual and collective power with all and all participants of this collaborative project that takes place at the interface of body, art, health and education.

Keywords: Art; Women; Territory; Education; Health;

\section{INICIAR UM TRAJETO: DESLOCAMENTOS, VELOCIDADES E LENTIDÕES}

Eis o que é bem menos espetacular do que "o movimento" ou "a revolução", mas mais decisivo. Ninguém poderá dizer aquilo de que um encontro é capaz. (COMITÉ INVISÍVEL, 2016, p. 37, grifo das autoras)

Esta viagem abrirá uma outra visão para você, e novas perspectivas podem surgir - deslocar-se daqui para lá é um desafio importante e confio nele; cheguei a conclusão de que cada experiência deve ser feita quando as possibilidades existem num determinado contexto. (OITICICA, 1969 in: FIGUEIREDO, 1998, p. 113)

De uns tempos para cá a palavra deslocamento tem aparecido com uma insistência que nos provoca e seduz. Fazemos parte de uma humanidade que se desloca. O sistema produtivo que potencialmente colonizou o planeta, o tal Capitalismo Mundial Integrado (GUATTARI, 1992) alimenta-se da circulação veloz de todo tipo de fluxos: "fluxos de capital, de informação, de imagem, de bens, mesmo e sobretudo de pessoas, enquanto produz novas formas de exploração e de exclusão" (PELBART, 2003, p. 21).

Assim, todos temos nos deslocado, espacial e geograficamente, de um país para outro, com muita insistência, mas não da mesma maneira, nem com a mesma autonomia, nem na mesma velocidade. Alguns de nós nos deslocamos porque, em nossa extrema inclusão no fluxo produtivo do capital, temos as fronteiras abertas e o chamado constante a estar quase que em dois lugares ao mesmo tempo, o que nos faz deslocarmo-nos com uma rapidez assustadora. Outros de nós nos deslocamos 
forçados pelos processos de mercantilização e comodificação de nossos recursos e bens que antes eram comuns; somos empurrados para fora de nossa terra e de nosso lugar, e o fazemos em um ritmo lento, porque carregamos o peso de nossos corpos e temos as fronteiras fechadas diante de nós.

A vida de todos nós fica em risco quando pautada por deslocamentos excessivos e acelerados que perdem o corpo ou por deslocamentos simultaneamente forçados e impedidos, que fazem o corpo pesar até o ponto de nos levar ao fundo do mar. Mas é claro que a vida de alguns de nós está muito mais em risco! O que evidencia também que a exclusão contemporânea tem uma coloração rítmica, que se caracteriza por cindir nas vidas e determinar, desde fora, onde há velocidade e onde há lentidão.

Esses riscos avassaladores ou apresentados a conta-gotas, indicam que vivemos uma desterritorialização brutal nos últimos anos, com crescente dissimetria, injustiça e desigualdade. $\mathrm{O}$ que nos coloca diante do desafio de repensar o tema das diferenças, das hibridações, das fronteiras, das itinerâncias e inventar novas terras, novas casas e novas comunidades que não têm, necessariamente, uma localização geográfica precisa, mas podem se constituir em "territórios sensíveis, afetivos, espaços de solidariedade, novos mapas de pertencimento e de afiliação translocais". (PELBART, 2003, p. 119)

É num mundo com tais qualidades, marcado por conectividade excessiva e exclusão maciça, que, subitamente e sem aviso, um fluxo viral interrompe tudo e nos faz parar. ${ }^{1}$ As fronteiras se fecham para todos, o mundo se reduz e a tensão passa a compor a coloração de nosso cotidiano.

Aterrorizados pela morte que ronda, mais perto (como sempre) de alguns que de outros, e desestabilizados por termos sido retirados do mundo que conhecíamos e seu ritmo, podemos nos isolar uns dos outros e nos desenraizar do mundo ainda

\footnotetext{
${ }^{1}$ Durante a escrita deste artigo, o planeta foi tomado por uma Pandemia do COVID- 19, que devido ao seu intenso grau de contágio e letalidade impôs o isolamento social em dimensão planetária.

Diante dos acontecimentos e dos diferentes efeitos nos corpos e nas vidas, outras camadas de pensamentos foram agregadas a análise prévia da nossa experiência, reafirmando muitos posicionamentos e deixando questões em aberto.
} 
mais. Mas podemos também, talvez alguns de nós, no meio do susto que nos sobrevêm, pausar, respirar e olhar em volta.

Respirar, ato constante e banal de nosso corpo, que subitamente se revela em sua importância e fragilidade, como direito universal no desafio de construir a possibilidade de uma vida respirável para todos. (MBEMBE, 2020, p. 11)

Será enfim possível experimentar e inventar.

um modo próprio de ocupar o espaço doméstico, de cadenciar o tempo comunitário, de mobilizar a memória coletiva, de produzir bens e conhecimento e fazê-los circular, de transitar por esferas consideradas invisíveis, de reinventar a corporeidade, de gerir a vizinhança e a solidariedade, de cuidar da infância ou da velhice, de lidar com o prazer ou a dor? (PELBART, 2003, p. 139).

Finalmente, talvez possamos verdadeiramente nos mover, agora quando muitos de nós, voluntariamente, se colocaram em confinamento e restringiram sobremaneira seus movimentos no espaço. Deleuze dizia que era pouco inclinado às viagens porque "é preciso não se mexer demais para não espantar os devires" (DELEUZE, 2000, p. 172). Devires que podem ser experimentados quando novas relações de velocidade e lentidão dissolvem formas, desprendendo movimentos, desembaraçando afetos. Recombinações de partículas mínimas que acontecem quando ficamos por muito tempo no mesmo lugar.

Talvez, então, possamos encontrar o lugar e o momento para exercitar pequenos deslocamentos - quase imperceptíveis e, no entanto, muito reais e potentes - em uma viagem diferente que pode nos abrir "uma outra visão" e fazer surgir "novas perspectivas". Como disse uma vez Hélio Oiticica (1969) em uma carta para Lygia Clark: "cada experiência deve ser feita quando as possibilidades existem num determinado contexto" (p. 113).

Entre algo que ainda ou quase não existe e a sua emergência neste mundo há um pequeno deslocamento na ordem das coisas: algo começa a esboçar-se, um embrião em germinação já começa a existir, mas é tão pequeno que quase não se pode ver. Para sentir e atestar sua realidade é preciso muita atenção e uma sensibilidade especial. Atenção e sensibilidade para reconhecer e sustentar a 
singularidade de processos de vir a ser desses esboços, dessas existências mínimas "que conquistam paulatinamente sua realidade, à medida que se tornam mais precisas e determinadas" (LAPOUJADE, 2017, p. 18).

\title{
2. EXPERIMENTAR PEQUENOS DESLOCAMENTOS
}

\begin{abstract}
Mais um dia de trabalho na região noroeste. Nos encontramos no portão da universidade para pegar duas vans que nos levam ao "outro lado do morro". Muitas vezes os corpos estão cansados das atividades intensas da semana, levando a um cochilar, outras vezes há um silêncio, mas também momentos de muita conversa e entusiasmo. O trabalho inicia ali. Os corpos precisam ganhar tonicidade, um estado de prontidão necessário a este tipo de proposta: buscar as mulheres em suas casas e levá-las a um equipamento de arte e cultura da região para que alguma experiência inventiva, sensível e principalmente coletiva possa acontecer (narrativa da docente pesquisadora).
\end{abstract}

Já muito antes da pandemia do Covid-19, o mundo dos grandes deslocamentos, nos impelia também a colocar em foco os pequenos deslocamentos que acontecem simultaneamente, compreendendo tal nos diz Latour (2020) em uma de suas entrevistas, que as micro-estratégias ou seja as ações individuais ou desenhadas como micropolíticas, não se encontram em oposição às macro-estratégias ou ações coletivas que resultam também em ações macropolíticas.

Queremos aqui dar visibilidade, a alguns aspectos de um projeto de criação e educação que envolve mulheres de uma região vulnerável de Santos/SP e alunos de cursos da saúde de uma universidade pública², no qual pequenos deslocamentos foram experimentados e assim colocar em foco essa ideia/ação, buscando afirmar o pequeno, o menor em sua positividade e como marcas microscópicas da experiência. Este reconhecimento da potência do menor, vai na contramão a uma "uma inabalável crença de que o maior é o local onde os acontecimentos ocorrem" (MANNING, 2019, p.12). Para a autora, enquanto os gestos majoritários da

\footnotetext{
2 Este artigo apresenta questões relacionadas ao projeto de pesquisa intitulada: Delicadas coreografias: práticas corporais e artísticas como produção de subjetividade, aprovado pelo Comitê de Ética da Universidade Federal de São Paulo - CEP/UNIFESP n:0232/2017
} 
macropolítica quantificam mais facilmente às mudanças ocorridas que podem alterar um campo, as tendências minoritárias sutis é que engendram as condições de toda e qualquer mudança (MANNING, 2019). No entanto, para mudarmos as nossas lentes e os nossos estados de atenção na tarefa de tornar perceptivos os micros acontecimentos presentes neste trabalho, é preciso inventar novos instrumentos, afiar os olhares e nos sensibilizar para o inobservável (RYNGAERT, 2009).

Observar e pensar sobre os pequenos deslocamentos tem sido uma questão que vem nos acompanhando há tempos e que se intensificou ainda mais neste período, onde o reconhecimento daquilo que parece pequeno, banal ou mesmo óbvio ganha importância imensa para lidar com toda ordem de desafios objetivos e subjetivos, individuais e coletivos que nos são impostos: uma reorganização/ invenção de nossos cotidianos, uma imersão nos vínculos presentes, nos modos de estarmos juntos e separados, nos riscos e prudências presentes em toda esta situação e inúmeros aspectos que tem sido fortemente debatidos, informados e compartilhados em nossas casas, mas prioritariamente por meio das redes sociais.

Considerando todo este outro contexto e na tentativa de dar continuidade ao processo de elaboração deste texto, buscamos articular alguns pensamentos voltados ao pequeno, aos detalhes, àquilo que se engendra nos quase silêncios encarnados nos corpos com toda a sua consistência e vitalidade. Buscamos revisitar a experiência com as mulheres da região noroeste de Santos, agora com os corpos atravessados pelos efeitos do momento da pandemia.

$\mathrm{Na}$ experiência aqui apresentada, estes pequenos deslocamentos são impulsionados (ou provocados) pelas linguagens artísticas, atravessadas por um trabalho minucioso com os corpos, para torná-los "sensíveis ao anódino, as marcas microscópicas das emoções apenas esboçadas, a um conjunto de detalhes que tecem a existência" (RYNGAERT, 2009, p.152). As artes com as suas diferentes linguagens acabam por funcionar nesta perspectiva, como dispositivos que podem engendrar movimentos menores que produzem alterações de tonalidade e/ou qualidade (MANNING, 2019) possíveis quando alguns estados de presença e atenção ao detalhe, podem ser vislumbrados. Neste momento, e com a 
intensificação da comunicação no espaço virtual, seguimos perseguindo uma poética nos encontros agora construindo um outro tipo de presença, apostando nos vínculos construídos ao longo de todos estes anos, resultantes das marcas produzidas por todas as nossas experiências.

\section{VARIAÇÕES DA MESMA EXPERIÊNCIA}

Para nos situar, esta proposta ${ }^{3}$ é realizada desde 2009 e vem ganhando camadas de aprofundamento, desafios e problematizações próprios de um processo de criação que repensa tanto o aspecto da formação dos alunos que dele participam, quanto das interferências realizadas junto às mulheres que vivem em um território bastante vulnerável em relação às condições de vida, saúde, econômico-sociais, ambiental, cultural e, portanto, existencial. A região noroeste, onde o trabalho acontece, é um território múltiplo composto tanto por habitações que guardam certa simplicidade, quanto de casas construídas sobre palafitas, moradias situadas em cima de rios poluídos, presença de bolsões de pobreza, tráfico de drogas, violência, etc. Também encontramos ali um Horto Florestal, uma rua principal com muitos mercados, um ginásio, um centro cultural, pracinhas, e muitos outros lugares que compõem esta "pequena cidade". Muitas das mulheres que participam de nosso grupo são migrantes do nordeste do Brasil e que foram buscar nesta região, um outro lugar para morar e seguir a vida.

O Grupo de Mulheres, tal como chamamos, é composto por uma média entre dez a doze mulheres e que apresentam, como todos, desafios de ordem física, mas também emocional, social, relacional, existencial. Poderíamos fazer uma narrativa extensa e sempre incompleta da vida de cada mulher, mas vamos nos ater a alguns acontecimentos que envolvem este projeto, trazendo experiências dos últimos anos, e tecer discussões sobre dimensões e desafios desta experiência artística-formativa a partir do conceito/ação pequenos deslocamentos em sua potência.

${ }^{3}$ Esta proposta pertence ao módulo Trabalho em Saúde e produção de cuidado, realizado no 3 ano de graduação nos dos cursos da área da saúde (Terapia Ocupacional, Educação Física, Nutrição, fisioterapia, Educação Física e Psicologia) da Universidade Federal de São Paulo, campus Baixada Santista Brasil. O grupo de alunos permanece em campo ao longo de um semestre. 
No entanto, cabe destacar que foram muitos os projetos realizados ao longo deste tempo ${ }^{4}$. Alguns deles foram mais livres, o grupo a cada semestre decidia o caminho a trilhar a partir do desejo dos participantes e outras vezes o projeto ganhava um contorno temático para que pudéssemos afinar e aprofundar algumas experiências. Como exemplo, podemos citar o Projeto Sonhos (LIBERMAN, FEDERICl, GUZZO, 2019), que nasceu depois de um tempo de maturidade do grupo e da necessidade de darmos este contorno temático a um processo de criação. Também servia como um norteador para os alunos, que muitas vezes chegam a este grupo com pouca bagagem para lidar com os deslocamentos presentes nesta proposta. Durante cerca de dois anos trabalhamos com o tema dos sonhos: sonhos dormindo, sonhos acordados, sonhos de futuro e muitos outros. Este projeto resultou em duas apresentações artístico-formativas no Instituto Arte no Dique, o equipamento de arte e cultura da região que nos acolhe todas as quartas-feiras a tarde.

Temos assim, além da dupla de docentes de diferentes áreas da saúde que coordena o trabalho e que se mantém como um "farol" ao longo do processo, praticamente dois grupos simultâneos: o grupo das mulheres e o grupo dos alunos. (LIBERMAN, MAXIMINO, 2015).

Além disso, profissionais do Instituto que participam em etapas pontuais do trabalho (no registro fotográfico, por exemplo, ou na participação em alguns encontros, entre outras parcerias).

Trabalhamos assim na interface entre o campo das artes, da saúde e da educação, o que permite habitarmos um território de fronteiras que dá uma complexidade singular a estes encontros e que não podem estar restritos a uma perspectiva rígida e única. Podemos dizer que estas ações no território são "um convite ao atravessamento e à transposição das fronteiras disciplinares, buscando a construção de um atendimento e de uma clínica para além das especialidades estanques, em favor de um trabalho coletivo num plano transversal a ser

${ }^{4}$ Outro projeto foi o Projeto Casas que aconteceu em paralelo às reuniões de quarta, envolvendo alunos do Projeto de projeto de Extensão Delicadas Coreografias, onde as interferências foram realizadas na casa das mulheres. 
permanentemente construído e cultivado" (KASTRUP, 2013, p.152).

Além disso, compartilhamos a concepção de formação em saúde trazida por Passos (2013) que indica que esta só pode ser pensada tomando a clínica como experiência transdisciplinar na invenção de outras formas de cuidado e de outras formas de relação com a realidade. Neste sentido a aventura clínica, é um saber-fazer que se faz na experiência, um saber imediato ao que acontece, isto é, um saber da experiência (PASSOS, 2013).

A arte, ou a experiência criativa passa a ter um papel importante, que convoca a presença dos estudantes e das participantes do grupo, assim como a ação inventiva dos docentes envolvidos, para pensar e produzir cada encontro, com ações que criem materialidades tangíveis: o canto, a dança, a narrativa, a performance. $\mathrm{O}$ importante é o processo e a entrega à experiência.

Partindo então destas premissas e em relação ao grupo de estudantes, podemos realçar a camada desta experiência que envolve a participação efetiva e conjunta dos alunos dos cursos da saúde (Terapia Ocupacional, Fisioterapia, Psicologia, Educação Física e Nutrição) na produção interdisciplinar do comum (TEIXEIRA, 2015), a partir de um " mergulho na experiência” (KASTRUP, 2013, p. 151) atravessada pelas linguagens artísticas ainda pouco exploradas e raramente oferecidas aos alunos desta área. Esta proposta produz em alguns deles, estranhamento, uma sensação de novidade e simultaneamente um campo fértil para descobertas pessoais, além de fomentar o desejo e o desafio da invenção de práticas cotidianas, em função das exigências concretas do território (KASTRUP, 2013) e daquilo que se apresenta a cada encontro. A presença destes jovens alunos produz um clima bastante singular no território e nas relações construídas com aquelas mulheres.

Tomando apenas estes aspectos já podemos observar a série de deslocamentos que a experiência pode produzir, mas focalizaremos a nossa atenção nas seguintes questões: que tipos de deslocamentos são produzidos neste trabalho e como reverberam os pequenos deslocamentos na sensibilidade e, portanto, na produção de outros modos de subjetivação dos participantes? 
São inúmeras as perguntas que temos feito e que não pretendemos responder, mas tateá-las para o exercício do pensamento, deixando muitas questões em aberto, como já elaboradas em outras produções ${ }^{5}$.

\section{PEQUENOS DESLOCAMENTOS: FORMAÇÃO E PRECARIEDADES}

A "precariedade" como método de trabalho é admitida na dimensão formativa com os estudantes, na medida em que não há um investimento em pré-requisitos e formas ideais para a prática artística, como tampouco temos a certeza daquilo que pode acontecer a cada encontro. A incompletude constante e a sensação imposta pela dura realidade das mulheres do grupo e as questões da vida dos alunos e de todos os participantes expressas e narradas pelos corpos, acopla-se bem aos fazeres inventivos e que privilegiam o momento presente dos encontros como sendo aquele o único possível.

Sem aviso prévio, os estudantes acabam por perceberem-se já dentro do turbilhão de criação e são obrigados a mobilizar de suas próprias histórias de vida, os recursos disponíveis, ainda que imprevistos, para a realização das propostas.

De fato, não se vislumbra qual seria um arremate possível do percurso formativo que se arrisca em vulnerabilidades próprias aos fazeres artísticos, que admitem limites mais fluidos. É justamente nestes estados de precariedade que a variação do menor, o surgimento dos pequenos deslocamentos, pode se efetuar.

Supõe-se aqui que experiências de formação não pretendem acompanhar os estudantes ou conduzi-los ao longo de toda a preparação profissional, que, na verdade, não termina nunca. Se elas forem capazes, contudo, de efetivamente preservar um inacabamento próprio a tudo que está vivo, nas interferências em campo em que a forma profissional (no estudante não acabado) ainda não 'pegou' inteiramente, caberá dali por diante a cada um assumir seus próprios desassossegos (CASETTO et al, 2016, p. 299-300).

\footnotetext{
${ }^{5}$ Para saber mais sobre as publicações e caminhos desse projeto acessar: https://delicadascoreo.wixsite.com/delicadas/o-projeto
} 
Tal perspectiva está afinada com uma proposta de formação cuja aprendizagem inclui a experiência e a invenção de problemas em contraposição a um processo de aprendizagem que se atem as formas prontas e à aquisição de informações. Seria o que denominou-se de uma formação "descentrada da experiência", isto é " aquela em que o vivido seria capaz de produzir deslocamentos, descentrar o sujeito, no contrafluxo do agir acrítico [...] como um movimento pendular entre vivência e gestos de interrupção, nos quais se possa sustentar o convívio com a incerteza e com a imprevisibilidade, assim como construir e desconstruir sentidos" (CAPOZZOLO et al, 2013).

Para isto, delineamos todo um campo de proposições, que parecem muitas vezes simples, mas que podem produzir pequenos deslocamentos que reverberam por exemplo, para os alunos, em outros modos de pensar e atuar em saúde, experimentando e observando processos que envolvem o campo das artes como propulsoras de movimentos menores nos corpos, na experiência e nos processos de criação engendrados nestes encontros.

Tais processos da ordem do menor, frequentemente considerados sem rigor, frágeis ou mesmo erroneamente inconsistentes por sua indeterminação ou "selvageria", tornam tais movimentos descartados, esquecidos ou ignorados. Porém é justamente ali que se encontra a sua força pois, "para manter sua vivacidade, ele (os processos menores) não precisa ter a força total daquilo que guarda o estatuto da preexistência, de uma métrica pré-determinada (...) inventando ritmicamente seu próprio pulsar (MANNING, 2019, p.13).

Para as mulheres não é diferente - cada proposta, mesmo que em um primeiro momento bastante simples, acaba por desafiá-las a experimentar o risco, o estranhamento, produzindo momentos de grande intensidade, com emoções à "flor da pele" reafirmando a beleza poética dos encontros. Consideramos que existe uma exigência de todos no sentido de arriscarmos nesta formação sensível e inventiva e que nos faz a todo o momento afinar um olhar e um exercício do pensamento para os movimentos menores, quase invisíveis nas experiências. Trata-se de reconhecer a sua potência disruptiva na contramão da desqualificação do pequeno ou do menor, 
situação tão frequente na subjetividade contemporânea.

As artes com sua linguagem expressiva aliada a um grau de presença dos corpos acabam por produzir afetos e criações que se fazem muitas vezes por pequenos acontecimentos, pequenos deslocamentos na sua continuidade habitual, muitas vezes automatizada e desprovida de sentido permeando os nossos cotidianos e nossa vida. Tais experiências nos fazem pensar e repensar nossos modos de estar no mundo, procurando talvez inventar outros.

Em cada encontro iniciamos em círculos e nos damos as mãos. Pedimos que cada um de nós "passasse a vista" pelo grupo, para nos darmos conta quem estava ali e com quem iríamos trabalhar no dia.

As expressões eram delicadas e fortes. Os olhares eram diferentes ora passando rapidamente, ora se demorando um pouco mais.

A Roda assim se formava para reafirmar o nosso vínculo, para nos situar naquele espaço, para habitar o que estava por vir. (Narrativa da docente pesquisadora)

Durante o período da Pandemia o contato foi realizado através da voz e reafirmava as tentativas sempre presentes de buscar o acesso e a aproximação com cada uma das mulheres. Mais uma vez observamos o grau de exigência para nos adaptarmos e criarmos a partir de uma situação real. Era pequeno e imenso o desafio de nos comunicarmos com cada uma delas. Um processo longo e lento apesar da velocidade dos acontecimentos. Quando conseguimos a conexão com cada uma delas, parecia que tínhamos realizado "um grande feito". Estas ações exigiam de nós deslocamentos nos modos de pensar a formação, de estarmos juntos, de prosseguir, mas reafirmava mais uma vez o objetivo do trabalho que é o de promover o acesso a uma experiência que se quer sensível e poética e que mesmo parecendo simples ou pequena, pode reverberar e provocar micro mutações que reverberam para todos os lados, criando marcas nos corpos e nas vidas de todos. (Narrativa da docente pesquisadora)

Naqueles encontros exercitamos, por exemplo, experimentar um movimento inabitual, emitindo um som inesperado, cantando uma música que gosta em companhia de outras pessoas, arriscando uma participação em um jogo proposto, arriscando olharmos um pouco mais uns para os outros, dar as mãos, tocar os corpos, falar e escutar entre tantos outros movimentos produzindo algum pequeno 
deslocamento nos modos de se estar presente nos encontros. "Gestos menores", que segundo Erin Manning (2019) funcionam como ativadores, portadores do acontecimento. "É a força capaz de portar a tonalidade afetiva da ressonância não-consciente, movendo-a para a articulação, penetrando na consciência de novos modos de existência" (MANNING, 2019, p. 15).

Atualmente, observamos que o grupo já tem uma "nova existência" resultante destes micro acontecimentos: gosta de cantar, conta muitas histórias, compartilha dores, sensações e sonhos, arrisca-se nas propostas mais e mais.

Algumas mulheres já reconhecem o seu lugar como "formadoras" destes alunos, invertendo aquilo que é usualmente esperado, ou seja, que professores e alunos estão ali para ensinar algo mantendo uma posição verticalizada do saber. Já se observa no grupo uma pequena inversão no sentido de tornar mais horizontalizada esta relação entre saberes e lugares - mais um pequeno deslocamento que "muda tudo".

Muitas vezes são as mulheres que recebem o novo grupo de alunos: explicam o que temos feito, ativam iniciativas, acolhem o jeito "desajeitado" destes em seus primeiros momentos, colocam seus corpos em estado aberto e poroso para o encontro. Gostam dos alunos e talvez de sua jovialidade. Podemos dizer assim que a intervenção não se faz apenas em um sentido, ou seja da universidade para as mulheres daquela comunidade, mas se faz entre cruzamentos, onde cada um ali ensina, aprende, bebe e baba (LYGIA CLARK,1980) 6 produzindo acontecimentos os mais variados, pequenos e grandes, atuando na micropolítica (ROLNIK, 2016) tão necessários nos dias de hoje (e talvez sempre), na construção sutil e delicada e também tensa e complexa de relações e experiências que envolvem diversidade e a produção de um comum.

Além de desafios relacionados ao momento político atual, que intensifica ainda mais os problemas que atravessam este tipo de formação e cuidado a estas populações, determinando "o possível" em uma atuação com esta complexidade, desde sempre lidamos com a vida de cada participante do grupo que se apresenta a

${ }^{6}$ Aqui nos referimos a obra Baba Antropofágica da artista Ligia Clark. CLARK, L. Lygia Clark. Textos de Lygia Clark, Ferreira Gullar e Mário Pedrosa. Rio: FUNARTE, 1980. 
cada vez que chegamos em suas casas. A cada vez que colocamos o dispositivo em funcionamento, uma série de eventos inesperados emergem: uma das participantes não está se sentindo bem e não quer ir ao encontro, outra quer ir, mas não está pronta, outra deseja que o grupo ou alguma estudante fique em sua casa ao invés de ir ao local dos encontros, outra tomou um excesso de medicação e está bastante confusa, outra chega visivelmente alterada no meio do encontro, nos deixando banhados por emoções que exigem outros encaminhamentos e nos arrastando para outra direção nos processos de cuidado e acolhimento, do desequilíbrio suscitado pela sua presença, entre inúmeras situações ora mais, ora menos desestabilizadoras dos processos. No entanto, podemos dizer que todas as situações são tomadas como modos de produzir perguntas, aprender, desafiar-nos, mesmo que muitas vezes não seja possível "fazer nada" para dar conta daquilo que se apresenta.

Em um dos ensaios, por exemplo, pensamos em utilizar um microfone. Nesta proposição foram inúmeros exercícios de levantar-se da cadeira, ir em direção ao microfone, amplificar a voz, aprender a se comunicar não mais com uma participante que está ao lado, mas para uma possível plateia. Todos estes exercícios, produzem pequenos deslocamentos que em algum momento ganham visibilidade. Margarida que tem dificuldade de se locomover por um problema que tem nas pernas, arrisca passinhos (milagrosos) em direção ao microfone. Pouco a pouco testemunhamos o seu processo de estar mais à vontade, vencer as vergonhas, arriscar outros modos de se apresentar para si mesma e para os outros.

Buscamos chamar a atenção dos alunos para estes pequenos deslocamentos e na complexidade de fazer aquilo que por vezes parece simples e óbvio: ter a iniciativa para levantar da cadeira, caminhar com toda uma plateia (o próprio grupo) olhando, estar em foco, arriscar um texto, ouvir uma outra voz saindo daquele corpo "pouco acostumado" a este tipo de desafio.

Nesta micropolítica, cada momento de afetação mútua busca ativar um encontro mais quente: momentos onde um aluno toma a frente na van e vai aprendendo a encontrar os caminhos por vezes difíceis de se chegar na região 
noroeste; um braço dado a uma mulher que tem dificuldade de subir na van, uma conversa cotidiana na entrada do equipamento sobre algum assunto que surge, a feitura de um bolo gostoso para regar os momentos de lanche comunitário sempre presente às quartas-feiras, um passo dado em uma dinâmica dançante por uma mulher que sofreu um trauma e que busca se ajustar em "seu novo corpo, sempre estranho", uma risada depois de uma fala engraçada, um choro depois de um desabafo e tantos pequenos momentos tão intensos que podem produzir uma marca nos corpos que indica que algo aconteceu ali, uma experiência estética efeitos dos encontros entre corpos e que se efetua a partir de propostas artísticas em suas múltiplas linguagens. Tais movimentos menores (MANNING, 2016) considerados até simples, por vezes quase invisíveis, podem comportar uma política do pequeno, do "passinho que parece um milagre".

\section{CONTORNOS FINAIS}

Como olhar para estas experiências realizadas no corpo a corpo, atravessadas pelos efeitos da pandemia que hoje nos exige um distanciamento presencial? Como identificar o que pode ser transposto para uma experiência virtual e o que perde potência quando os encontros presenciais estão impedidos de acontecer?

Nosso desafio seria encontrar caminhos possíveis para chegar até cada uma delas sabendo que apenas algumas tinham acesso ao computador e internet. O convite foi feito e nós docentes e alguns alunos estávamos conectados por uma ferramenta virtualmente. Iniciamos a primeira tentativa com a Dona Vera que não tem computador. Fiz uma ligação telefônica deixando na viva voz a nossa conversa para que todos pudessem escutá-la e falar. Dona Vera ficou muito alegre ao ouvir a nossa voz e a meu ver "Deu uma aula" para todos: Disse que estava bem, se cuidando e que só saia ali pertinho para ir à padaria. Nos contou ainda que seguia pintando os seus panos de prato, cozinhando, fazendo as suas coisas e que sentia saudades dos alunos da UNIFESP e dos encontros das quartas-feiras. Também repetiu várias vezes que se sentia muito grata por conhecer muitos alunos, tecer amizades e que muitas delas seguem em contato, fazem parte de sua vida. Falou para o novo grupo de alunos das atividades que vinha realizando como a hidroginástica e de como era bem cuidada e principalmente do seu desejo em conhecê-los pessoalmente e retornar ao nosso grupo. Saí desse encontro virtual, banhada de alegria e contagiada pela força da Dona Vera. (Narrativa da docente pesquisadora) 
Atravessados pela pandemia, iniciamos um trabalho com os alunos através de uma ferramenta digital. Nossa proposta com eles (que havíamos encontrado presencialmente em uma única vez), foi a de tentar entrar em contato com as mulheres do grupo para saber como estão neste período de isolamento social.

A precariedade que já era constitutiva do projeto se fez mais presente, no compartilhamento de uma sensação que nos toca a todos nesses tempos que correm. O vírus que se espalha pelo mundo tem o poder de evidenciar que a comunidade humana é igualmente precária (BUTLER, 2020). E diante desse acontecimento e sua revelação, que suspende as formas de encontro e compartilhamento, somos tomados pelo desejo de inventar uma outra experiência, acolhendo outros deslocamentos.

Em um jogo entre acompanhar as mulheres, contribuir na formação dos estudantes e lidar com os inúmeros imprevistos relacionados aos problemas de se atuar em uma região bastante vulnerável, de tecer uma parceria com os profissionais do equipamento que nos acolhe a cada semana, além de lidar com todas as questões que envolvem a vida de cada participante deste projeto (alunos, docentes, mulheres, profissionais), buscamos produzir algum tipo de deslocamento, nomeadamente da ordem do pequeno para podermos avançar em algum aprendizado a partir das experiências e viver juntos processos de criação, momentos de descobertas e aventura.

Consideramos importante destacar alguns destes desafios uma vez que explicitam em ato, as condições reais de precariedade não somente da região, nem tampouco da formação, mas da própria vida, rompendo com qualquer tipo de idealização de um trabalho artístico a ser tecido, e afirmar que é dentro destas vulnerabilidades que algo, um pequeno deslocamento, pode acontecer. Arriscamos pensar que talvez seja justamente esta condição de precariedade que nos faz olhar as experiências por uma ótica dos pequenos deslocamentos, dos movimentos menores que atuam e atravessam nas e pelas proposições e decisões a cada encontro do grupo. 
Podemos observar que na maioria das vezes que aquelas mulheres que conseguem participar do projeto, expressam o desejo do encontro, explicitado pelo seu sorriso ao visualizar a van chegando na esquina, no abraço ao aluno que vai acompanhá-la, no figurino caprichado com que se vestem para as quartas-feiras, pela conversa que acontece assim que nos vemos na expectativa de serem escutadas nas suas questões mais emergentes e na vontade de estar com o grupo nas propostas que vamos inventando juntos. Também os alunos explicitam como são afetados pelos encontros com as mulheres trazendo em seus diários de campo (GUZZO et al, 2019; GOULART et al, 2018) narrativas sobre intensidade desta experiência. Considerando então todos os elementos ali presentes, cada quarta-feira é regada por uma tonalidade que vai sendo modelada a cada vez em nosso trabalho no território e como estratégia e resposta para lidar com as asperezas e suavidades da vida, reafirmando mais uma vez que as linguagens artísticas e a experiência estética neste estar juntos podem produzir um pequeno, mas potente deslocamento.

Nesta vida que por vezes pulsa, ao mesmo tempo tensa, delicada, densa e leve, buscamos valorizar os pequenos deslocamentos possíveis, levar os alunos a atentar a estes movimentos menores, por vezes até invisíveis para que possamos prosseguir.

É preciso uma sensibilidade muito especial e aguda para dar atenção a esses movimentos menores que se presentificam em nosso corpo através de sensações ínfimas, quase imperceptíveis, ativando pequenas percepções que nos permitem captar algo do invisível (GIL, 1996).

Reforçamos, assim, a necessidade e possibilidade de usar o próprio corpo para sentir, perceber e estabelecer contato e conexão a partir de pequenos gestos como oferecer o braço para a senhora que tem dificuldade de caminhar de sua casa até van, dar um sorriso quando as mulheres se aproximam, olhar nos olhos, abrir os braços, chamar pelo nome, sentar-se ao lado, colocar um degrau na van para facilitar o acesso da participante na subida do carro. Soma-se a isso toda a gama de experiências artísticas que vamos propondo pouco a pouco em cada encontro, que oportunizam o exercício da presença, do "estar ao lado" e produzir um comum. 
Por fim, e agora atravessados pela pandemia de SARS-Cov-2 e seus efeitos, reafirma-se o pequeno deslocamento como força propulsora para continuidades e mutações. Precisamos mais do que nunca ativar em cada um de nós a capacidade de experimentar o prazer de estar vivo, de dançar, de cantar. Como disse Ailton Krenak, há por toda parte "pequenas constelações de gente espalhada pelo mundo que dança, canta, faz chover" (KRENAK, 2019, p. 26). Neste momento, apesar de muitos aprendizados, inclusive com a invenção e usos das tecnologias virtuais, reafirmamos um projeto que se realiza presencialmente, no corpo a corpo, pois é através de suas marcas que podemos hoje prosseguir e acreditar que estamos, com muitos outros, construindo um mundo por vir.

\section{Agradecimentos especiais da Flavia Liberman:}

Agradeço imensamente ao Prof. Conrado Federici, meu parceiro nesta experiência delicada, potente e divertida, aos alunos e alunas que participaram e participam deste projeto e principalmente a cada uma das mulheres com quem aprendemos a vontade de prosseguir.

\section{REFERÊNCIAS}

BUTLER, J. O capitalismo tem seus limites. In: AMADEO, P. (org.) Sopa de Wuhan: pensamiento contemporáneo en tiempos de pandemias. Madrid: Editorial ASPO, 2020.

CASETTO, S. J.; HENZ, A. O.; GARCIA, M. L.; AGUIAR, F. B.; MONTENEGRO, J. T.; UNZUETA, L. B.; CAPOZZOLO, A. A. A good training based on insufficiency: Work in health care as an ethics. Journal of Health Psychology, v. 21, p. 291-301, 2016. Disponível em: https://doi.org/10.1177/1359105316628747. Acesso em: 26 abr. 2020.

CAPOZZOLO, A.A.; IMBRIZI, J.M.; LIBERMAN, F.; MENDES, R. Formação descentrada na experiência. In: CAPOZZOLO, A. A.; CASETTO, S. J.; HENZ, A. O. (org.). Clínica Comum: itinerários de uma formação em saúde. São Paulo: Hucitec, 2013. pp.124-150.

COMITÊ INVISÍVEL. Aos nossos amigos. São Paulo: Ed. n-1, 2016.

DELEUZE, G. Conversações. São Paulo: Ed. 34, 2000.

GIL, J. A imagem nua e as pequenas percepções. Lisboa: Relógio D'Água, 1996.

GUATTARI, F. Caosmose. São Paulo: Ed. 34, 1992.

GOULART, P. M.; PEZZATO, L. M.; JUNQUEIRA, V. Experiências narrativas: um relato de 


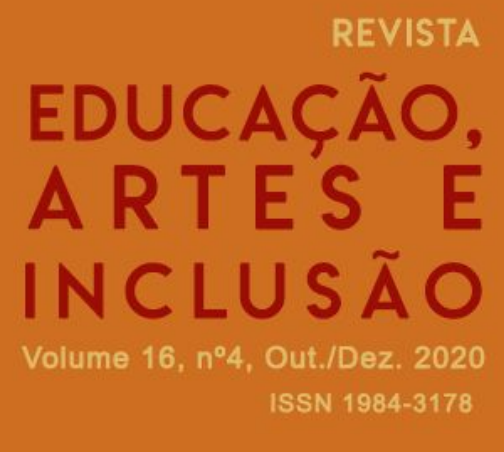

ROLNIK, S. A hora da micropolítica. São Paulo: Editora n-1, 2016.

TEIXEIRA, R. As dimensões da produção do comum e a saúde. Saúde Soc., v. 24, supl.1, pp.27-43, 2015. Disponível em: http://dx.doi.org/10.1590/S0104-12902015S01003. Acesso em: 26 abr. 2020

Recebido em: 25/06/2020

Aprovado em: 13/07/2020 